\title{
A Patient with Acro-osteolysis Syndrome: Hajdu-Cheney
}

\author{
Ali Şahin ${ }^{1}$, Mehmet Sezgin Pepeler ${ }^{2}$ and Naoto Shimbori ${ }^{2}$
}

Key words: acro-osteolysis syndrome, Hajdu-Cheney, hands, feet

(Inter Med 49: 87-88, 2010)

(DOI: 10.2169/internalmedicine.49.2850)

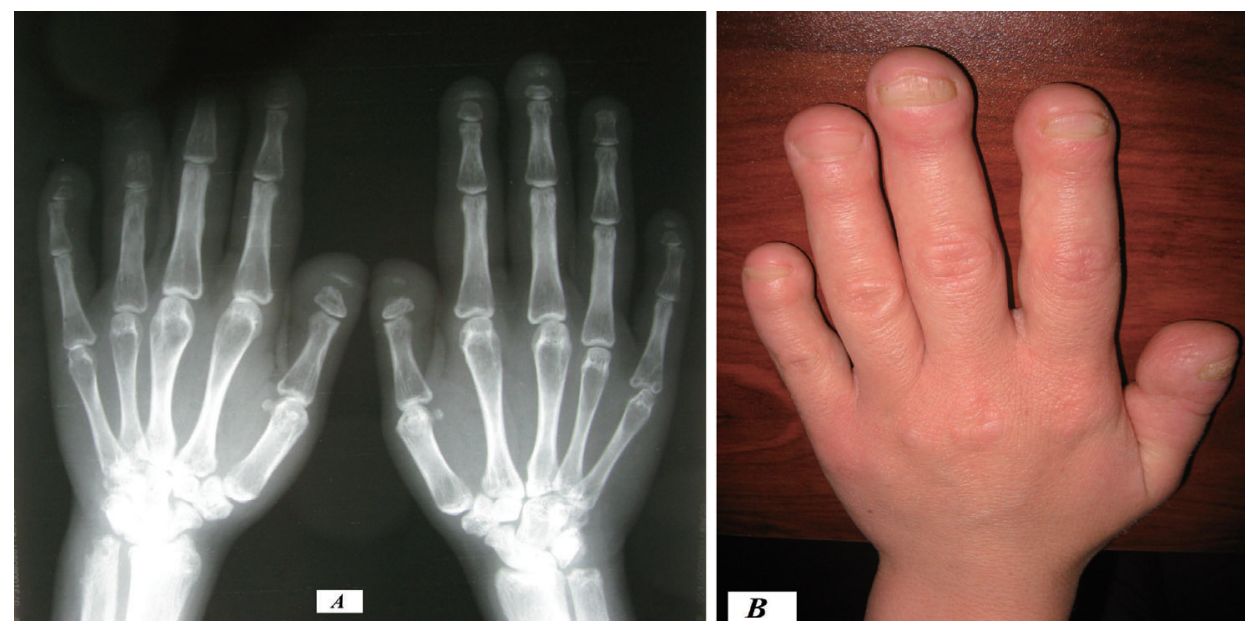

Picture 1. Radiograph of hands showing mid-phalangeal resorption of terminal phalanges (A). Shortening of fingers, and metacarpals of the left hand $(B)$.

Hajdu-Cheney syndrome is an autosomal dominant acroosteolysis syndrome, in which clinical and radiological abnormalities develop at different stages of life.

A 26-year-old woman visited our rheumatology clinic for progressive shortening of her terminal phalanges. Radiographs showed acro-osteolysis and classic midphalangeal band-like resorption of the terminal phalanges affecting multiple digits of both hands and feet as shown in Pictures 1 and 2.

The differential diagnosis for these radiological changes includes severe Raynaud's phenomenon, polyvinyl chloride exposure, thermal injury (frostbite, burns), snake or scorpion bites, hyperparathyroidism, trauma, the acro-osteolysis syndromes (mandibuloacral, Hajdu-Cheney or Giaccai syndromes), Rothmund's syndrome (autosomal recessive with poikiloderma, cataracts, saddle nose, sparse hair/eyelashes, small stature, skeletal/dental abnormalities, telengiectasia, hypogonadism), or Wormian bone disorders (e.g., osteogenesis imperfecta, progeria), which can be distinguished by clinical features $(1,2)$.

The present patient had features of Hajdu-Cheney syndrome, an autosomal dominant disorder characterised by short stature, distinctive craniofacial changes (frontal bossing, broad nose with flared nostrils, coarse thick hair, low set ears), slowly progressive acro-osteolysis of the distal phalanges. The full phenotype is rare, if ever, present in childhood, and different clinical and radiological abnormalities develop at different stages in the lifespan and often progress with age. However, acro-osteolysis and concomitant digit abnormalities are present in most individuals with Hajdu-Cheney syndrome and thus, radiographic findings make the diagnosis possible before clinical signs and symptoms are fully developed (3). On her laboratory tests; RF, ANA, immunoblot (anti-Scl 70, anticentromer, anti-Ro, antiLa etc.) were negative. Anti-dsDNA, anti-CCP, erythrocyte sedimentation rate (ESR), C-reactive protein (CRP) were normal, and parathyroid hormone level was normal (42.1 $\mathrm{pg} / \mathrm{mL}$, normal range: 12-88 $\mathrm{pg} / \mathrm{mL}$ ). Similar deformities

${ }^{1}$ Clinical Immunology and Rheumatology Department, Ankara University Medical Faculty, Ankara, Turkey and ${ }^{2}$ Internal Medicine Unit, Ankara University Medical Faculty, Ankara, Turkey

Received for publication September 3, 2009; Accepted for publication September 10, 2009

Correspondence to Dr. Ali Şahin, dralsahin@hotmail.com 


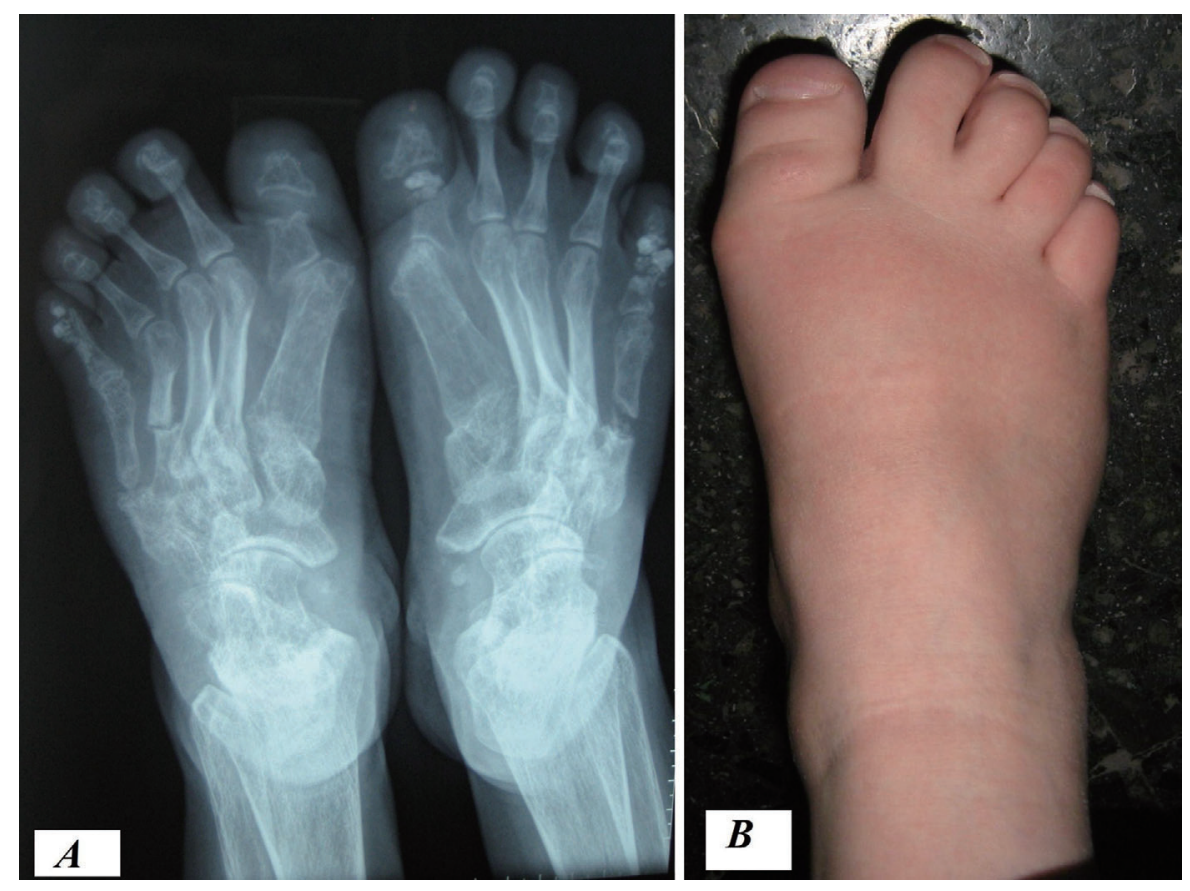

Picture 2. Radiograph of feet showing mid-phalangeal resorption of terminal phalanges, fractures due to osteoporosis, and joint deformities (A). Shortening of toes of the right foot (B).

which are related to rheumatic diseases (scleroderma, severe Raynaud's phenomenon) can be observed in radiological in- vestigations, therefore rheumatologists should be aware of such acroosteolysis syndromes.

\section{References}

1. Letchumanan P, Thumboo J, Leong RT. A patient with progressive shortening of the fingers. J Rheumatol 36: 198-199, 2009.

2. Marik I, Kuklik M, Zemkowa D, Kozlowski K. Hajdu-Cheney syndrome: Report of a family and a short literature review. Austra- las Radiol 50: 534-538, 2006.

3. Brennan AM, Pauli RM. Hajdu-Cheney syndrome: Evolution of phenotype and clinical problems. Am J Med Genetics 100: 292310, 2001.

\footnotetext{
(C) 2010 The Japanese Society of Internal Medicine http://www.naika.or.jp/imindex.html
} 